\title{
«HOLA, GUAPA, ¿CÓMO ESTÁS?»: USOS VOCATIVOS DEL ADJETIVO DE BELLEZA GUAPO EN EL ESPAÑOL PENINSULAR CONTEMPORÁNEO
}

\author{
Fien De LatTE \\ Universidad de Gante (Bélgica) \\ Research Foundation Flanders (Bélgica)
}

\section{RESUMEN}

En el español hablado, son varias las expresiones vocativas que señalan una relación afectiva entre los interlocutores. Entre estos llamados vocativos cariñosos se destaca el uso de los adjetivos de belleza como señal de afecto y cariño hacia el interlocutor. El presente estudio se dedica a las principales características formales y funcionales del vocativo derivado del adjetivo de belleza guapo en el español peninsular contemporáneo. Para ello, se ha recurrido a datos provenientes de varios corpus orales de la variedad peninsular. Los resultados ponen en evidencia que guapo constituye un vocativo multifuncional, prestándose a usos fático-apelativos, corteses y expresivo-enfáticos. No obstante, los hablantes emplean este vocativo preferiblemente como estrategia de intensificación cortés, con el fin de realzar la imagen del interlocutor. En este estudio, se alega que las propiedades pragmáticas del vocativo bajo análisis se originan en el contenido conceptual de la base léxica, más precisamente en el sema halagador inherente al significado de los adjetivos de belleza. Los usos vocativos de guapo se presentan, pues, como el resultado de un proceso de pragmaticalización.

PALABRAS CLAVE: vocativo; adjetivos de belleza; cortesía; pragmaticalización; español oral.

\section{ABSTRACT}

In spoken Spanish, a wide variety of vocative expressions is used to signal an affective, close relationship between the interlocutors. Within this paradigm of the so-called terms of endearment, aesthetic adjectives stand out as markers of affection and tenderness towards the interlocutor. The present study sheds light on the main formal and functional characteristics of the Spanish vocative guapo, derived from the aesthetic adjective, meaning 'pretty, handsome', in present-day Peninsular Spanish. The analysis is based on data from different oral Peninsular Spanish corpora. The results show that guapo is a multifunctional vocative, whose pragmatic-functional paradigm includes phatic-appellative, politeness and 
expressive-emphatic uses. However, guapo is preferably used as an intensifying politeness strategy, in order to boost or enhance the face of the interlocutor. Hence, it is claimed that the pragmatic properties of the vocative under scrutiny originate in the conceptual content of the lexical base, more specifically in the flattering value inherent to the meaning of aesthetic adjectives. Therefore, the vocative uses of guapo are presented as the result of a pragmaticalization process.

KEYWORDS: vocative; aesthetic adjectives; politeness; pragmaticalization; spoken Spanish.

Fecha de recepción: 29/11/2019

\section{INTRODUCCIÓN}

En una interacción verbal, no son infrecuentes las expresiones mediante las cuales los hablantes se dirigen directamente al interlocutor. A estas expresiones nos referimos con el término vocativo (Leech 1999; Cuenca 2004; Kleinknecht 2013). En castellano, como en la mayoría de las lenguas modernas, varias categorías léxicas son susceptibles de funcionar como vocativo. Suelen distinguirse las siguientes macro-categorías:

1) los nombres propios (Juan, Pepa);

2) las formas de tratamiento nominales y adjetivales (tio/a, joven);

3) los títulos (señor[a], don/doña); y

4) los pronombres de segunda persona (tú, usted) (Braun 1988; Alonso Cortés 1999).

Aunque los nombres propios se consideran los vocativos prototípicos por su capacidad de identificar unívocamente a un referente contextualmente conocido (cf. el interlocutor), los hablantes recurren con frecuencia a vocativos cariñosos, que subrayan la relación positiva y afectiva entre los interlocutores, especialmente en el registro coloquial (Cuenca 2004; Edeso Natalías 2005). Al respecto, son ilustrativas las palabras de Fernández Ramírez (1951: 496-497 apud Edeso Natalías 2005), quien afirma que «... el vocativo es con mucha frecuencia un aporte de acentos afectivos de mayor o menor intensidad». El español cuenta con un abanico de expresiones cariñosas empleadas como forma de tratamiento en interacciones cotidianas, como por ejemplo las formas prototípicas amor, cielo y cariño. Se prestan igualmente a usos vocativos expresiones interpretadas como piropos o cumplidos, entre las cuales se destacan los adjetivos de belleza, como precioso, hermoso y guapo. Este artículo tiene como objetivo analizar los usos vocativos del adjetivo de belleza guapo en el español peninsular contemporáneo. 
Como afirma Corominas (1980-1991 apud Provencio Garrigós 2016), «es sabido que hoy guapo es en España la expresión más popular de la idea de 'hermoso' [...], quizá pasando por la noción vecina 'ostentoso, galán y lucido en el modo de vestir y presentarse'». En su estudio de 2016, Provencio Garrigós traza con detalle la curiosa evolución semántica del adjetivo guapo. La autora concluye que guapo ha experimentado un cambio semántico meliorativo, desde la percepción olfativa y gustativa hacia la visual: originando del latín vappa 'vino desvirtuado, evaporado', ha llegado a significar en castellano, entre otros, 'bien parecido', 'acicalado, bien vestido' El uso vocativo de guapo, ya documentado en textos del siglo XVIII (Provencio Garrigós 2016) y, como será mostrado en este análisis, no infrecuente en el lenguaje espontáneo actual, se especifica de la manera siguiente en el diccionario de la Real Academia Española: 'en vocativo, vacío de significado, como expresión de cariño, a veces con retintín o con tono de irritación. Cállate un poquito, guapo' (DLE en línea). Sin embargo, hasta la actualidad, faltan estudios que indaguen en el uso de este adjetivo como vocativo.

Dentro del paradigma de los adjetivos de belleza en español (bello, bonito, hermoso, lindo, majo, precioso), guapo se destaca por su referencia prototípica a entidades humanas ${ }^{2}$. Además, contrariamente a bello, hermoso y precioso, el adjetivo objeto de estudio no incorpora en su significado el sema de "perfección', ni tampoco pertenece exclusivamente al registro literario o formal, o como en el caso de majo, al registro coloquial. Esta semántica neutra, que comparte con bonito, lo hace propicio a aparecer en diversos contextos, poco especializados. Sin embargo, asumimos que es especialmente su aplicación prototípica, y única dentro del paradigma de los adjetivos de belleza, a referentes humanos la que explica por qué guapo constituye el adjetivo de belleza que más naturalmente se presta a usos vocativos, por lo menos en España, puesto que el español americano muestra usos y significados muy diferentes de los mismos adjetivos (cf. DLE en línea; DEA 1999; Moliner 2008).

Como se puede desprender de lo antedicho, los usos vocativos de guapo han surgido de manera motivada, originándose en el propio lexema adjetival de base a través de un proceso de gramaticalización (cf. §1). Consideramos, en otros términos, que los valores vocativos de guapo se han activado a partir de las propiedades semánticas, morfológicas y distribucionales de la base léxica, de modo similar a la articulación de los marcadores del discurso a partir de una base nominal, adjetival o verbal (Mosegaard Hansen 1998; Tanghe 2016). Efectivamente, varios análisis empíricos ya han indicado

\footnotetext{
1 Para la entrada completa de guapo, véase el DLE en línea <https://dle.rae.es/>.

${ }^{2}$ Solo en el lenguaje juvenil y vulgar puede referirse a referentes inanimados (Moliner 2008; p. ej. Y aquí la piscina está guapa, mira [COLAm]).
} 
correlaciones significativas entre las características morfosintácticas, semánticas y funcionales de elementos pragmáticos, inclusive los vocativos (Leech 1999; Briz Gómez y Pons Bordería 2010). Es de esperar por tanto que guapo presente determinadas características formales según su funcionamiento pragmático-discursivo.

Ante esta descripción panorámica surgen varias preguntas, entre otras, ¿bajo qué formas y con qué frecuencia aparece el vocativo guapo en el lenguaje oral?, ¿qué valores semántico-pragmáticos expresa y qué propósitos discursivos cumple en el discurso?, y ¿qué aspectos de su significado conceptual favorecen su empleo como vocativo? Teniendo en cuenta estas preguntas de investigación, el presente artículo se propone proporcionar un análisis formal y funcional detallado de los usos vocativos del adjetivo de belleza guapo en el español peninsular contemporáneo, los cuales se presentarán como el resultado de un proceso de gramaticalización.

De acuerdo con estos objetivos, el análisis se estructura de la manera siguiente: la primera sección se centra en el cambio lingüístico subyacente al desarrollo de los usos vocativos del adjetivo de belleza bajo análisis. En la segunda sección presentaremos la metodología y los datos empíricos a la base del análisis empírico. La tercera sección examina las principales características formales del vocativo guapo, más específicamente su variación morfológica y su comportamiento posicional en el enunciado, al igual que las funciones pragmáticas que cumple en el discurso. La cuarta sección se dedica a las conclusiones del estudio.

\section{EMERGENCIA DE LOS USOS VOCATIVOS DE GUAPO: UN CASO DE GRAMATICALIZACIÓN}

Claro está que, para poder funcionar como vocativo, guapo ha experimentado un proceso de cambio lingüístico, al igual que otros vocativos afectivos derivados de nombres comunes, como por ejemplo niño/a, frecuentemente dirigido a un oyente que ya ha pasado la época de la niñez, o hijo/a, que se destina a menudo a un interlocutor con el que el hablante no tiene ningún lazo sanguíneo (Cuenca 2004; Tanghe 2016). De ahí que se pueda afirmar que estas formas de tratamiento, que señalan una relación cercana y afectiva entre los interactuantes, han perdido en mayor o menor medida su significado referencial originario. Esta desemantización o "palidecimiento' del significado conceptual revela sintomáticamente el proceso de cambio lingüístico subyacente al desarrollo de sus usos vocativos, el cual presentaremos en términos de gramaticalización, definida como el proceso de cambio lingüístico en el que ítems léxicos adquieren (nuevas) funciones gramaticales (Garachana 1999). 
No obstante, cabe precisar que los vocativos no constituyen elementos gramaticales en sentido estricto ${ }^{3}$, por lo que no encajan en la teoría de la gramaticalización estricta. Por tanto, en este análisis la gramaticalización debe interpretarse en sentido amplio, más precisamente como «un macrocambio dinámico que engloba distintas subclases y procesos» (Company Company 2004). De gran interés para los vocativos en específico es que este macrocambio incluye igualmente el proceso mediante el cual piezas léxicas desarrollan significados (inter)subjetivos y pragmático-discursivos, al que se refiere en términos de pragmaticalización (Dostie 2004; Ghezzi 2014). Teniendo en cuenta las propiedades semánticas y sintácticas de guapo en su forma gramaticalizada, asumimos que la pragmaticalización, como subclase de la gramaticalización en sentido amplio, es el proceso que más apropiadamente permite dar cuenta del desarrollo de los usos vocativos de guapo.

Más en concreto, los ítems pragmaticalizados, o en vías de pragmaticalización, se caracterizan -en resumidas cuentas- por (a) un blanqueamiento semántico más o menos progresivo del significado referencial etimológico, paralelo al desarrollo de valores pragmáticos, y (b) una mayor independencia sintáctica (Traugott 1995a; Dostie 2004; Tanghe 2016). Estos 'síntomas' se manifiestan todos en los usos vocativos de guapo, como ilustra el siguiente ejemplo (1):

(1) No desayunes tú, guapa, que estás inmensa. (CORPES XXI: Bravo Aquilar 2010)

Como podemos observar, a consecuencia del blanqueamiento semántico subyacente a la pragmaticalización, en función vocativa guapo no alude necesariamente a la belleza, o ni siquiera al aspecto físico del interlocutor. Así, según el comentario del hablante 'que estás inmensa', es muy poco probable que la interlocutora le parezca 'guapa' en sentido estricto ${ }^{4}$. No obstante, cabe señalar que este blanqueamiento semántico se ve compensado por el desarrollo de varios valores pragmáticos, de manera que se habla más bien de un enriquecimiento pragmático (Loureda Lamas y Pons Rodríguez 2015: 345), que suele resultar en la conformación de formas

${ }^{3}$ Esta carencia de estatus gramatical sintáctico se refleja en primer lugar en su no integración en la estructura sintáctica de la predicación (cf. infra). Se observa asimismo una reducción de sintaxis, puesto que en su uso vocativo el adjetivo de belleza prescinde de sus capacidades de complementación (no suele aceptar la presencia de complementos: *Hola, guapa de cara) y determinación ( ${ }^{*}$ Hola, la guapa). Esta autonomía de la predicación y cancelación de sintaxis afirman su difícil encaje en la gramaticalización 'estricta', la cual genera elementos más gramaticales, con mayor anclaje sintáctico (Company Company 2004).

${ }_{4}^{4}$ De esta manera, el ejemplo viene a confirmar la observación de Braun (1988), quien postula que el valor conceptual de la expresión vocativa contradice en ocasiones las características del oyente. 
polifuncionales (cf. §3.2). Este aumento de fuerza pragmática supone que los elementos lingüísticos se recargan de (nuevos) significados pragmáticos y valorativos permeados por los diferentes tipos de contextos en que se manifiestan $^{5}$ (Company Company 2004). Luego, en el plano sintáctico, se observa que guapo tiene carácter extrapredicativo. Es decir, no forma parte de la estructura sintáctica oracional, siendo separado del resto de la oración por una pausa más o menos marcada en la oralidad, la cual suele estar señalada por una coma en textos escritos (Bañón 1993).

Ahora bien, como ya se ha señalado, los valores pragmáticos adquiridos por una forma pragmaticalizada no son arbitrarios, sino que surgen a partir de las propiedades semánticas, morfológicas y distribucionales de la forma léxica de base, considerada por tanto como la fuente de los demás significados derivados (Traugott 1995b; Ghezzi 2014). Son los procesos conceptuales, entre los cuales se destacan las extensiones metafóricas o metonímicas, la generalización y la especialización, los que activan esos significados derivados (Tanghe 2016). Claro está que, cuanto más desemantizada sea la forma, menos significado conceptual tendrá y más información procedimental contendrá ${ }^{6}$. Así, una misma forma puede retener más o menos información conceptual según su función pragmática y grado de desemantización correspondiente. Esta idea se ilustrará a continuación mediante dos ejemplos reales del vocativo guapo:

(2) a. MAORE2J03: Muchas felicidades guapísima. (COLAm)

b. A: Tú no has trabajado en tu vida.

B: Anda que tú, guapo, que te tenemos que sacar de la cama.

(CREA oral)

En concreto, como ilustra el ejemplo (2a), cuando guapo se une como vocativo cariñoso y halagador a un acto valorizador de imagen, como por ejemplo una felicitación, transmite más información conceptual y manifiesta por tanto un grado de desemantización menos avanzado que cuando el mismo vocativo acompaña a una reprimenda, con valor de irritación o con retintín, alejándose progresivamente del valor referencial de belleza originario. Esta desemantización es obvia en el ejemplo (2b), donde el

${ }^{5}$ En el ejemplo (1), es difícil determinar con precisión el valor expresado por el vocativo por falta de información situacional. Aunque proponemos una interpretación como recurso cariñoso suavizador, no se excluye tampoco la posibilidad de que guapa se haya producido precisamente con el fin de humillar al interlocutor, cargándose de un valor sarcástico.

${ }^{6}$ En palabras de Blakemore (1987), las unidades lingüísticas con significado procedimental contienen una instrucción, indicando cómo se ha de interpretar el enunciado en el contexto comunicativo. Sin embargo, como bien indica Moeschler (2002), el contenido conceptual no se pierde por completo en cuanto la forma adquiera nuevos significados procedimentales, sino que ambos contenidos coexisten, constituyendo un continuo semánticopragmático de valores más o menos gramaticalizados (cf. infra). 
hablante $\mathrm{B}$ refuerza su réplica al reproche que le lanza el interlocutor A mediante el vocativo guapo, que en este caso difícilmente puede interpretarse como expresión de cariño.

Se trata por tanto de un continuum que se compone de dos extremos semánticos:

Figura 1. El blanqueamiento semántico de guapo

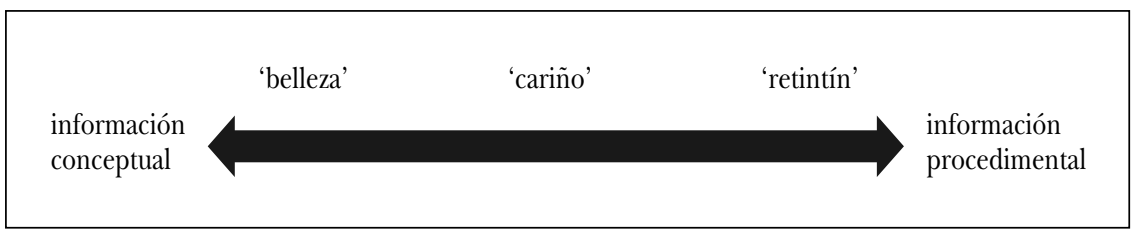

En el polo izquierdo se sitúa el significado conceptual original de belleza y el extremo derecho corresponde al valor de retintín, que constituye el significado más alejado del contenido descriptivo originario. En el intermedio se encuentran, pues, los valores de halago y de afecto que, ya presentes en el significado referencial original, pasan al primer plano en cuanto el sema descriptivo de belleza se desvanece en los usos pragmaticalizados ${ }^{7}$. Los significados de halago y cariño se pueden explicar como una extensión metafórica, en la que el dominio de la belleza física se proyecta al dominio de la belleza interior. Por otro lado, aunque está codificado en su significado pragmaticalizado (cf. DLE en línea), el valor de retintín es evidentemente cancelable dada la polisemia de la forma. La interpretación sarcástica se ve desencadenada por el contexto y las circunstancias específicas en que aparece el vocativo. En resumidas cuentas, el contexto (extra)lingüístico y la intención comunicativa del hablante, entre otros factores, permiten especificar en qué punto del continuum se encuentra la ocurrencia concreta de guapo.

De todos modos, como veremos más adelante (cf. §3.2), la baja ocurrencia de contextos en que guapo transmite valores negativos confirma su proliferación y uso prototípico como vocativo positivo, halagador y cariñoso, tal y como lo indica el DLE ${ }^{8}$. No obstante, en el mismo diccionario, la descripción del significado del vocativo guapo como 'vacío de significado' no

${ }^{7}$ A estos significados se suman varios otros valores secundarios, los cuales, como no forman parte de su significado convencional, se consideran más apropiadamente sentidos desencadenados por el contexto.

${ }^{8}$ Gracias a su valor prototípicamente afectivo y halagador, el vocativo guapo valoriza la imagen del destinatario y, de esta manera, logra realzar las relaciones interpersonales, por lo que su empleo puede considerarse intrínsecamente cortés. A la hora de analizar las funciones pragmáticas cumplidas por el vocativo bajo análisis, se describirá elaboradamente el vínculo entre los vocativos y la cortesía (cf. §3.2.1). 
parece acertada. A la hora de comentar las funciones pragmático-discursivas, volveremos sobre los diferentes grados de pragmaticalización y desemantización observables en las ocurrencias de guapo.

Para concluir este apartado, conviene centrarnos brevemente en la motivación de los procesos de gramaticalización. A nuestro parecer, en el caso específico de guapo resultan particularmente relevantes dos conceptos cognitivos centrales en las teorías del cambio lingüístico, a saber la ritualización y la (inter)subjetivización. Primero, con el fin de dar cuenta de la pérdida más o menos progresiva del significado conceptual de guapo, conviene recurrir al concepto de la 'ritualización', tal y como definida por Haiman (1994) en su teoría de la gramaticalización. Es decir, al igual que los ritos culturales, que pierden fuerza simbólica en cuanto se usan de manera más frecuente, los elementos lingüísticos también pierden parte de su contenido informativo en cuanto surgen más frecuentemente en el discurso (Enghels 2018). Al mismo tiempo, el debilitamiento de la información conceptual posibilita el desarrollo de nuevos valores simbólicos y procedimentales, inferidos a partir del contexto. Como se desprende de esta teoría, y como han confirmado otros autores (i.a. Bybee 2003; Company Company 2004), la frecuencia de uso de un ítem léxico desempeña un papel primordial como motor en los procesos de cambio lingüístico. Efectivamente, hemos visto que dentro del paradigma de los adjetivos de belleza en castellano, guapo sobresale como la expresión de belleza preferida en España (cf. §0). Su alta frecuencia en el discurso español, la que hace que aparezca en variados tipos de contextos, y aún más importante, su especialización en la referencia a entidades humanas, lo convierten en el adjetivo de belleza más propicio al desarrollo de usos vocativos. En breve, su uso 'ritualizado' hace que la forma también se aplique a contextos que no remiten específicamente al aspecto físico del referente.

Igualmente implicada en el macrocambio de gramaticalización es la (inter)subjetivización, definida como el proceso a través del cual se incorpora progresivamente al hablante y al interlocutor en el significado del elemento lingüístico (Cuenca y Hilferty 1999). En concreto, en sus usos pragmaticalizados guapo funciona al nivel (inter)personal, transmitiendo información acerca de las relaciones entre hablante e interlocutor, y/o expresando las valoraciones del hablante ante lo comunicado o elementos contextuales (cf. §3.2). Sin embargo, como adjetivo de belleza, guapo se define por naturaleza como un adjetivo evaluativo, cuyo significado léxico lleva codificado el juicio estético sobre la entidad referida, perteneciente al mundo externo (McNally y Stojanovic 2017). De esta manera, se puede alegar que los usos (inter) subjetivos de guapo conllevan una reorientación evaluativa del mundo externo hacia las relaciones interpersonales y el mundo interno de emociones y sentimientos. 
A modo de conclusión intermedia, en sus usos pragmaticalizados guapo tiende a retener el valor positivo y halagador, derivado directamente del sema evaluativo inherente al adjetivo de belleza de origen. Por causa de una proyección metafórica del mundo externo hacia las relaciones interpersonales y la subjetividad, el valor de apreciación positiva pasa al primer plano en cuanto guapo reorienta su enfoque funcional del nivel ideacional al (inter) personal. Incluso, en contextos negativos, el vocativo puede cargarse de un matiz de retintín, uso en que su valor positivo de cariño se anula, evidentemente. Como posibles motivaciones del cambio semánticopragmático experimentado por guapo han sido alegados los procesos de ritualización e (inter)subjetivización. Ahora bien, antes de pasar al análisis más detallado de ejemplos reales, cabe presentar los datos empíricos a la base del presente estudio.

\section{Datos y Metodología}

El presente estudio se basa en datos provenientes de siete corpus orales del español, a saber, el Corpus Oral de Madrid (CORMA 2016-2019) ${ }^{9}$, Val.Es.Co. 2.1, COLAm, CREA oral, CORPES XXI (oral), COSER y CORLEC. Los datos, todos de carácter conversacional y espontáneo, provienen de contextos dialógicos, incluyendo conversaciones coloquiales (CORMA, COLAm, Val.Es.Co. 2.1, CORLEC), entrevistas mediáticas en la radio o televisión (CREA oral, CORPES XXI), y entrevistas semi-dirigidas (COSER). Además, todos los datos fechan desde los años noventa del siglo anterior (CREA oral, COSER) hasta la actualidad (CORMA) y son producidos por hablantes masculinos y femeninos, de diferentes edades, que viven en la Península ${ }^{10}$.

Como el análisis se centra en la variedad peninsular, se han descartado todos los ejemplos procedentes de las variedades americanas en los corpus generales (CREA oral, CORPES XXI). Es más, tres corpus representan

9 Este corpus, elaborado por el equipo de Lingüística Española de la Universidad de Gante, recopila 100 conversaciones, equivalentes a aproximadamente 59 horas de grabación, de tono informal entre hablantes madrileños, y realizadas en diferentes ámbitos comunicativos. Como representa el habla de hombres y mujeres, de diferentes generaciones y de diferentes clases sociales, el corpus constituye un muestreo representativo del habla capitalina actual (Enghels, De Latte y Roels 2020).

${ }^{10}$ El uso de varios corpus implica evidentemente ciertas limitaciones y dificultades, relacionadas fundamentalmente con diferencias en la disponibilidad y clasificación de datos metalingüísticos, especialmente de índole sociológica (Briz Gómez 2012). Así, la mayoría de los corpus, salvo el CREA oral, informan sobre el sexo y la edad de los hablantes, mientras que se observa un déficit informativo acerca del nivel sociocultural de los mismos en todos los corpus consultados. De todos modos, por limitaciones de espacio, se ha dejado fuera de análisis el uso variable del vocativo guapo en correlación con variables sociológicas. 
datos exclusivos de la variedad madrileña (COLAm, CORMA) o valenciana (Val.Es.Co. 2.1), por lo que pueden indicar tendencias diatópicas en el uso del vocativo objeto de análisis. Los datos se han recopilado mediante la búsqueda por el lema guapo, seleccionando únicamente las ocurrencias en las que guapo cumple una función vocativa ${ }^{11}$ (3a). Los usos adjetivales (3b) se excluyen evidentemente del banco de datos:
(3) a. 4F1: Siéntate guapa. (CORMA)
b. ¿Qué perrito más guapo! (CREA oral)

La tabla 1 especifica el resultado de la recopilación de datos en cada corpus, indicando las frecuencias absolutas y relativas, en orden decreciente. También se presentan las frecuencias normalizadas (fn) por 10000 palabras, puesto que los corpus no contienen el mismo número de palabras:

TABLa 1. Distribución de los datos del corpus

\begin{tabular}{lrrrcc}
\hline \multicolumn{1}{c}{ Corpus } & \# & \% & $\begin{array}{c}\text { total palabras } \\
\text { corpus }\end{array}$ & fn & $\begin{array}{c}\text { año de } \\
\text { recopilación }\end{array}$ \\
\hline CORMA & 38 & 35,2 & ca. 320401 & 1,2 & $2016-2019$ \\
CREA oral & 28 & 25,9 & no disponible & no disponible & $80-90$ \\
\hline COLAm & 16 & 14,8 & ca. 456000 & 0,4 & $>2000$ \\
COSER & 15 & 13,9 & ca. 1800000 & 0,08 & $90>2000$ \\
\hline CORPES XXI (oral) & 8 & 7,4 & ca. 3136671 & 0,03 & $>2000$ \\
Val.Es.Co. 2.1 & 2 & 1,9 & ca. 73344 & 0,3 & $>2000$ \\
\hline CORLEC & 1 & 0,9 & ca. 1100000 & 0,009 & 90 \\
\hline Total & $\mathbf{1 0 8}$ & $\mathbf{1 0 0}$ & & & \\
\hline
\end{tabular}

Como muestran estas cifras, el CORMA encabeza la lista con 38 ejemplos $(35,2 \%)$, seguido por el CREA oral, que proporciona 28 ocurrencias $(25,9 \%)$. El COLAm y el COSER presentan frecuencias semejantes, el CORPES XXI ha generado pocos ejemplos, al igual que el CORLEC y el corpus Val.Es.Co., aunque las frecuencias normalizadas indican que la forma está más documentada en este último corpus que en el COSER, el CORPES XXI y el CORLEC.

Ahora bien, el hecho de que guapo se registra más frecuentemente en el CORMA, uno de los dos corpus exclusivamente madrileños, puede ser un

${ }^{11}$ El banco de datos incluye todas las variantes morfológicas del vocativo, incluyendo formas superlativas, aumentativas y compuestas (cf. $§ 3.1$ ). 
indicio de que se manifieste más frecuentemente en la variedad capitalina que en otras zonas de la Península, como por ejemplo en el español de Valencia, donde el mismo vocativo aparece con menos frecuencia según los datos del corpus Val.Es.Co. ${ }^{12}$. Además, su predominio en el corpus más actual de la lista conduce a la hipótesis de que guapo se esté volviendo más productivo en el paradigma de vocativos en el español coloquial actual ${ }^{13}$.

A pesar del tamaño bastante reducido del banco de datos, los 108 ejemplos constituyen un muestreo representativo del uso del vocativo guapo en las últimas décadas en el español peninsular y forman por tanto una base válida para el propuesto análisis, de índole fundamentalmente cualitativa. Suponemos que este decente número de ocurrencias se debe sobre todo a la alta competición entre las numerosas expresiones vocativas de uso en español. Así, cabe concluir que a pesar de que el empleo del vocativo guapo no sea excepcional, tampoco es omnipresente en el lenguaje oral ${ }^{14}$.

\section{ANÁLISIS FORMAL Y FUNCIONAL}

En lo que sigue, se presentarán y comentarán detalladamente las principales características formales y funcionales del vocativo guapo en el español hablado. Dada la relación genética entre las propiedades semánticas y morfosintácticas de la base léxica y sus significados pragmaticalizados derivados (cf. §1), comprobaremos en el análisis empírico si su naturaleza semántica favorece o, en cambio, retiene determinados usos vocativos y además, cómo sus usos pragmáticos se reflejan formalmente, aludiendo a las propiedades morfológicas y distribucionales del vocativo.

\subsection{Caracterización formal}

En primer lugar, conviene echar un vistazo a las variantes morfológicas tanto flexivas como derivativas del vocativo guapo encontradas en los corpus:

${ }^{12}$ De todos modos, como disponemos de un conjunto de datos bastante reducido, es difícil extraer conclusiones tajantes en cuanto a esta supuesta variación diatópica.

${ }^{13}$ Esta hipótesis se ve afirmada además por el hecho de que el CORLEC, un corpus de los años noventa, presenta la frecuencia normalizada más baja de la lista. De todos modos, hará falta comprobar este aparente incremento en la productividad del vocativo mediante un estudio (micro-) diacrónico más amplio.

${ }_{14} \mathrm{Al}$ comparar las frecuencias del vocativo guapo en el CORMA (1,2 por 10000 palabras) con las de tío (6,5 por 10000 palabras), otro vocativo de uso general, se nota que el primero no constituye una forma predominante en el habla actual. 
TABLA 2. Variación morfológica del vocativo guapo

\begin{tabular}{lrc}
\hline variantes morfológicas & $\#$ & \% \\
\hline guapa & 68 & 63 \\
guapo & 16 & 14,8 \\
guapas & 7 & 6,5 \\
guapos & 2 & 1,8 \\
guapísima & 10 & 9,3 \\
guapetona & 2 & 1,8 \\
guapetonas & 1 & 0,9 \\
\hline cosa guapa & 1 & 0,9 \\
\hline chico guapo & 1 & 0,9 \\
\hline Total & $\mathbf{1 0 8}$ & $\mathbf{1 0 0}$ \\
\hline
\end{tabular}

Primero, llama la atención la alta frecuencia de la forma femenina guapa $(\mathrm{n}=68 ; 63 \%)$, frente a una escasa frecuencia del equivalente masculino guapo $(\mathrm{n}=16 ; 14,8 \%)$, lo que sugiere que los hablantes prefieren utilizar el vocativo bajo análisis para dirigirse a una destinataria femenina (cf. §3.2). Igualmente, las formas plurales guapos/guapas alcanzan una frecuencia relativamente baja $(\mathrm{n}=9 ; 8,3 \%)$, lo que revela que el vocativo suele ir dirigido a un solo interlocutor. Conviene señalar al respecto que esta tendencia puede deberse a las características contextuales de las interacciones analizadas, a saber, puede que haya más intercambios entre dos individuos que entre un individuo y un grupo de interlocutores ${ }^{15}$.

Segundo, salta a la vista que los corpus no solo presentan variantes de género y número sino también formas morfológicamente modificadas mediante un sufijo derivativo. Estas formas producen un efecto intensificador, reforzando el valor semántico-pragmático de afecto y halago expresado por el vocativo:

(4) MAMTE2J01: Hola guapisima felicidades dieciséis eh. (COLAm)

Efectivamente, podemos derivar de este ejemplo que la presencia de un sufijo (guapísima) tiene como efecto la intensificación del valor afectivo y

15 No obstante, ha sido demostrado que el uso de uno u otro vocativo viene condicionado, entre otros parámetros, por el número de personas al que va destinado el vocativo. Así por ejemplo, los jóvenes prefieren recurrir a la forma chavales para apelar al grupo entero de interlocutores, mientras que otras formas de uso expandido, como tío o macho, apenas se registran en su forma plural (De Latte y Enghels 2019). Se disciernen igualmente vocativos cuya forma plural se considera agramatical, como por ejemplo hombre $/{ }^{*}$ hombres. 
halagador del vocativo. En cambio, las formas aumentativas (guapetón/ona) constituyen formas lexicalizadas, con el significado de 'valentón, atrevido' (DLE en línea). Sin embargo, como vocativo, también puede considerarse una expresión de cariño intensificada (5):

(5) Coral un beso, guapetona. (CREA oral)

Como ilustran los ejemplos precedentes, estas formas intensificadas se prestan con menor facilidad a un uso como expresión de valores negativos, puesto que suelen combinarse con enunciados valorizadores de imagen (cf. §3.2).

Luego, se han hallado dos casos en que guapo se aúna a un nombre para funcionar juntos como vocativo afectivo, a saber, cosa guapa (6a), una forma bastante curiosa para referirse a una persona, y chico guapo (6b). Aunque pueda sugerirse que en este tipo de sintagmas guapo funciona como adjetivo calificativo adjunto, conservando su valor léxico de belleza, prevalece claramente el valor semántico-pragmático de cariño, proximidad y confianza transmitido por la expresión sintagmática ${ }^{16}$ :

(6) a. PEL3F1: Hola cosa guapa, buenos días caballero.

b. PEL3F1: Hola chico guapo.

CPEL4F5: Buenos días. (CORMA)

Desde el punto de vista distribucional, los vocativos se caracterizan por una gran libertad posicional, moviéndose prototípicamente en la periferia izquierda (7a) o derecha (7b) del enunciado ${ }^{17}$, aunque no es infrecuente su posicionamiento intermedio (7c) o incluso su aparición independiente (7d), en cuyo caso el vocativo constituye un acto de habla por sí solo (Bañón 1993; Alonso-Cortés 1999):

(7) a. I1: Guapa, que tengas suertecica y que no te falte el trabajico.

b. I1: Así que eso es todo, guapas. (COSER)

(COSER)

c. MALCE4G03: Aquí de mi niño no sé qué yo guapa no sé qué yo iba con un cacho allí. (COLAm)

d. MAMTE2G01: ¡Guapa! (COLAm)

${ }^{16}$ Cabe señalar que puede tratarse de un uso idiosincrásico, puesto que ambos vocativos fueron emitidos por la misma persona, a saber, una peluquera que saluda a dos de sus clientes.

${ }^{17}$ El enunciado se define como «el segmento de discurso que corresponde a una acción independiente, a una intención determinada del hablante. Es aislable en tanto posee fuerza ilocutiva propia y es identificable por la presencia de ciertas marcas lingüísticas prosódicas y semánticas» (Albelda et al. 2014: 39). 
Varios autores ponen de relieve que la posición en el enunciado de elementos discursivos, como marcadores del discurso y vocativos, se correlaciona con el valor pragmático expresado por estos (Bañón 1993; Briz Gómez y Pons Bordería 2010; Tanghe 2016). Así, según Gili Gaya (1961: 214 apud Bañón 1993), aunque la posición sintáctica ocupada por el vocativo es gramaticalmente indiferente, no lo es desde el punto de vista pragmático, ya que el vocativo expresa diferentes valores pragmático-discursivos según su posición en el enunciado. La tabla 3 resume las frecuencias distribucionales de guapo:

TABLA 3. Frecuencias de las posiciones de guapo en el enunciado

\begin{tabular}{lrr}
\hline Posición EN EL ENUNCIADO & \multicolumn{1}{c}{$\#$} & \% \\
\hline inicial & 3 & 2,8 \\
media & 37 & 34,2 \\
final & 60 & 55,6 \\
independiente & 8 & 7,4 \\
\hline Total & $\mathbf{1 0 8}$ & $\mathbf{1 0 0}$ \\
\hline
\end{tabular}

Ahora bien, la posición inicial es considerada en la literatura como la posición 'más natural' de los vocativos, dada su función prototípica de apelación: se llama la atención del interlocutor al inicio de una intervención (Leech 1999; Jørgensen 2008). No obstante, los datos revelan que guapo tiende a aparecer en las posiciones final $(n=60 ; 55,6 \%) y$, en segundo lugar, media ( $\mathrm{n}=37 ; 34,2 \%$ ), asociadas principalmente con valores reforzadores y atenuadores (García Dini 1998; Cuenca 2004). Esta afirmación se ve apoyada por el hecho de que las variantes morfológicas intensificadas guapísima y guapetona suelen aparecer en posición media o final del enunciado (cf. § 3.2). Así, teniendo en cuenta esta correlación entre la posición y el valor pragmático-discursivo, suponemos que guapo tiende a especializarse en funciones de atenuación e intensificación. Esta hipótesis constituye el punto de partida del análisis funcional.

\subsection{Funcionamiento pragmático-discursivo}

Aunque la función principal de los vocativos consiste en llamar la atención del oyente, no restringen su potencial pragmático a esta función básica (i.a. Cuenca 2004; Kleinknecht 2013). El vocativo bajo análisis no consti- 
tuye una excepción a esta polifuncionalidad propia de los vocativos. Este apartado estudia las funciones pragmáticas asumidas por guapo y comprueba además si su significado prototípicamente adulador y afectivo favorece determinados usos vocativos. Dada su carga semántica cariñosa, suponemos que guapo cumple principalmente funciones de atenuación e intensificación cortés.

Con el fin de determinar la función pragmática ejercida por guapo, es preciso tener en cuenta criterios objetivos, como, desde el punto de vista formal, la posición ocupada por el vocativo en el enunciado y la presencia de afijos apreciativos intensificadores $(\mathrm{cf} \text {. } \$ 3.1)^{18}$. Luego, también el contexto lingüístico en que el vocativo se inserta incide en importantes medidas en la interpretación pragmática del vocativo (i.a. Edeso Natalías 2005; Kleinknecht 2013). Con 'contexto' entendemos más precisamente el tipo de acto de habla con el que se combina el vocativo (asertivo de información; asertivo de opinión; interrogativo; directivo; expresivo), la actividad de imagen involucrada en el acto de habla (valorar; mantener; mitigar; amenazar; auto-proteger), el tipo de intervención del que forma parte guapo (iniciativa; reactiva; reactivo-iniciativa), y la presencia de marcadores pragmáticos u otros vocativos ${ }^{19}$. Estos parámetros resultan de suma importancia, puesto que el vocativo suele teñirse del valor ilocutivo de la partícula discursiva o del enunciado al que acompaña (Edeso Natalías 2005).

Cabe señalar que el vocativo es capaz de expresar varios valores pragmáticos en una sola ocurrencia, aunque siempre se destaca una función predominante, determinada a base de los criterios de análisis antedichos. En concreto, se han identificado tres macro-funciones en el corpus, a saber, las funciones de atenuación y refuerzo cortés, la función fático-apelativa, y la función expresivo-enfática. La tabla 4, en página siguiente, presenta las frecuencias de las funciones pragmáticas de guapo en orden decreciente.

Estas frecuencias indican que guapo se utiliza principalmente como vocativo cortés, lo que confirma nuestra hipótesis con respecto a la relación entre el significado del vocativo y su funcionamiento discursivo, tal y como será mostrado a continuación mediante ejemplos concretos del corpus. Además, los resultados corroboran la existencia de una correlación entre

${ }^{18}$ Desafortunadamente, a pesar de su importante incidencia en la interpretación de los vocativos, el análisis de las características prosódicas está fuera del alcance del presente estudio.

${ }^{19}$ Los casos en que guapo se combina con otro elemento pragmático-discursivo, las llamadas coocurrencias, no son infrecuentes $(\mathrm{n}=25 ; 23,1 \%)$. Distinguimos entre los distintos tipos de coocurrencias las con un marcador pragmático (oye, mira, venga, anda, bueno, no sé qué, vale, muybien) $(\mathrm{n}=20 ; 80 \%)$, las con una interjección (ay sî) $(\mathrm{n}=2 ; 8 \%)$ y las con otro vocativo, que corresponde en todos los casos a un nombre propio $(n=3 ; 12 \%)$. En todas estas coocurrencias, guapo se pospone al marcador o al otro vocativo. 
TABLA 4. Las funciones pragmático-discursivas de guapo y sus frecuencias

\begin{tabular}{lll}
\hline \multicolumn{1}{c}{ Funciones } & $\#$ & \% \\
\hline funciones corteses & 64 & 59,2 \\
intensificación cortés & 50 & 46,2 \\
\hdashline atenuación cortés & 14 & 13 \\
\hline fático-apelativa & 29 & 26,9 \\
\hline expresivo-enfática & 15 & 13,9 \\
\hline Total & $\mathbf{1 0 8}$ & $\mathbf{1 0 0}$ \\
\hline
\end{tabular}

la posición y el valor pragmático-discursivo del vocativo, puesto que las funciones de intensificación y atenuación se presentan más frecuentemente en el medio o al final del enunciado, donde guapo se sitúa más frecuentemente (cf. §3.1).

\subsubsection{Las funciones de intensificación y atenuación cortés}

Como marca explícita del interlocutor en el texto, el vocativo vehicula intrínsecamente información con respecto a la relación interpersonal, estando por tanto involucrado en las actividades de cortesía y en los trabajos de imagen ${ }^{20}$ (face work; Brown y Levinson 1987). La cortesía (verbal) puede definirse como el conjunto de normas y estrategias lingüísticas que regulan la dinámica interpersonal durante una interacción verbal (Haverkate 1994). Como veremos más adelante, la función prototípica de apelación de los vocativos puede relegarse a un segundo plano cuando los hablantes recurren a ellos con el único (o principal) propósito de 'ser cortés' hacia el interlocutor (Alonso-Cortés 1999).

${ }^{20}$ La imagen, fundamental en los análisis de la cortesía verbal, designa metafóricamente la personalidad del individuo como miembro de la sociedad de la que forma parte (Haverkate 1994: 18). Proviene del término face en inglés, que significa literalmente 'cara'. Según el sociólogo Goffman (1972), durante una conversación los hablantes construyen una imagen social (face) y desean conservarla. En palabras de Hernández Flores (2004: 95), la imagen social «... no es inamovible, sino que puede perderse, mantenerse o realzarse» y se compone de dos polos complementarios, uno positivo y otro negativo. La imagen positiva corresponde a la imagen que los individuos tienen de sí mismos, así como su deseo (face-wants) de que los demás miembros de la sociedad la reconozcan y la refuercen, mientras que la imagen negativa concierne el deseo de cada individuo de que sus intenciones no sean impedidas por otros (Brown y Levinson 1987). 
Uno de los aportes más significativos acerca del papel de los vocativos como estrategia de cortesía en español es el estudio de Edeso Natalías (2005), quien distingue dos funciones de cortesía, partiendo de la distinción de Kerbrat-Orecchioni (2004) entre los Face Flattering Acts (FFAs) y Face Threatening Acts (FTAs), basada en la actividad de imagen implicada en el acto de habla. La primera categoría, en español 'actos agradadores de imagen', incluye los actos de habla de carácter cortés, que satisfacen intrínsecamente la imagen del interlocutor por transmitir respeto y reconocimiento hacia el destinatario, como por ejemplo los agradecimientos, los cumplidos, los acuerdos, y las invitaciones. Según la autora, los vocativos que acompañan a un FFA tienden a intensificar el valor ilocutivo de este tipo de actos de habla. Efectivamente, el corpus ofrece ejemplos en que guapo refuerza un saludo (8a), una felicitación (8b), y una despedida (8c), considerados como actos que realzan la imagen del oyente:

(8) a. 3F1: Hola, guapa, ¿qué tal? (CORMA) ${ }^{21}$

b. MAORE2J03: ¡Muchas felicidades guapísima! (COLAm)

c. I: Muchas gracias por haber llamado y jviva Vallecas!

E: Hasta luego guapo.

I: Hasta luego. (CREA oral)

Es más, en (8b) el valor cortés transmitido por guapo viene intensificado por el sufijo superlativo -ísima. Es interesante señalar al respecto que la gran mayoría de las formas intensificadas mediante un pre- o sufijo ( $\mathrm{n}=13 ; 12 \%$ del total de ejemplos) asumen usos corteses, más precisamente una función de intensificación cortés $(\mathrm{n}=11 ; 84,6 \%)$, situándose principalmente en el medio $(n=4 ; 30,8 \%)$ o al final del enunciado $(n=8 ; 61,5 \%)$. De esta manera, los datos corroboran una vez más el estrecho vínculo entre las características funcionales, distribucionales y morfológicas de los elementos pragmáticos.

Luego, guapo también cumple un propósito cortés en combinación con otro vocativo, que siempre tiene la forma de un nombre propio, como en el ejemplo (9a), donde la forma intensificada guapísima especifica la relación social -afectiva, cariñosa- entre los interlocutores, realzando así el vínculo interpersonal. Fíjese en que el hablante recurre una segunda vez a guapa para desearle suerte al interlocutor, lo que evidentemente también se considera un acto cortés. Igualmente, se pueden considerar usos de

${ }^{21}$ Con respecto a (8a) y (8c), puede sugerirse que el vocativo cumple una función fática, abriendo y cerrando el contacto con el interlocutor. No obstante, cabe señalar que esta función fática la cumplen las mismas interjecciones hola y hasta luego, consideradas como rutinas corteses de saludo y despedida. Los vocativos constituyen un apoyo al carácter cortés de estas expresiones, de manera que les atribuimos una función de intensificación cortés. 
intensificación cortés los casos en que guapo se yuxtapone a un marcador pragmático que expresa aceptación o acuerdo, como vale y muy bien (9b):

(9) a. Hola Belén guapísima quería aprovechar para decirte que sé que todo va a salir genial y te mando un beso y un abrazo enorme isuerte guapa! (CORPES XXI)

b. CPEL4F1: Cuatro con cincuenta, ¿no? Cuatro con cincuenta es que no tengo yo suelto para ver $(())$

PEL3F1: Vale muy bien guapa. Te veo la semana que viene. CPEL4F1: Pues sí. (CORMA)

En cambio, los FTAs, 'actos amenazadores de imagen', corresponden a aquellos actos de habla que suponen una posible amenaza a la imagen del interlocutor, de manera que podrían provocar un desequilibrio en la dinámica interpersonal, como en el caso de actos exhortativos, críticas o reproches. Acompañando a un FTA, los vocativos funcionan regularmente como mecanismo de atenuación, constituyendo un recurso eficaz para atenuar los efectos hirientes subyacentes a este tipo de enunciados, como un acto exhortativo (10a) o un aviso que podría interpretarse como una crítica $(10 \mathrm{~b})$ :

(10) a. ROPAe4F1: Toma, pasa ahí el trapito guapa. ROPAj3F2: Bueno gracias, hermosa. (CORMA)

b. CPEL4F6: Me estás lavando con agua fría eh guapa. (CORMA)

Vale la pena fijar la atención en la presencia del vocativo hermosa en (10a), en la intervención reactiva al turno donde aparece guapa. Al igual que guapa, el vocativo hermosa se deriva de un adjetivo de belleza expresando una valoración apreciativa hacia el destinatario. En este contexto específico, es posible que la propia presencia de guapa estimule el uso de un vocativo semejante en el turno sucesivo. Podríamos hablar por tanto de un efecto 'priming', definido como el proceso psicológico subconsciente mediante el cual la exposición a determinados estímulos ('guapa') repercute en el comportamiento (verbal) subsecuente de un individuo ('hermosa') ${ }^{22}$ (Bentin et al. 1985).

El hablante puede asimismo recurrir al vocativo para atenuar el valor exhortativo expresado por el marcador apelativo al que acompaña. Este es el caso en (11), donde guapo se adjunta a oye con el fin de suavizar el grado de imposición subyacente a este marcador apelativo, que funciona

${ }^{22}$ No obstante, el uso de hermoso en función vocativa es más bien excepcional, porque este adjetivo estético alude a una belleza que integra 'perfección', 'moralidad', y 'espiritualidad' (DEA 1999; Moliner 2008). No sorprende por tanto su vinculación prototípica con el registro formal, incluso pulido, por la cual se presta menos a usos vocativos en el lenguaje oral. 
a su vez como introductor de un acto de habla exhortativo, y por tanto potencialmente amenazante a la imagen del interlocutor ${ }^{23}$ :

(11) A: Porque no porque no te puedes pagar la letra de un coche.

B: Oye, guapo, pues cómprate un segunda mano, si no tienes dinero para otro.

En suma, como expresión amalgamada de piropo y afecto, guapo suele transmitir cortesía, alabando y realzando la imagen del interlocutor ${ }^{24}$. Puede considerarse por tanto un vocativo prototípicamente cortés. No sorprende pues que los hablantes 'exploten' su valor positivo, utilizando guapo principalmente como refuerzo de actos valorizadores de imagen y, en menor medida, como atenuador cortés de actos amenazantes. Así, nuestros datos vienen a confirmar las palabras de Edeso Natalías (2005), quien postula que la propia naturaleza léxica del vocativo lo hace idóneo para adquirir determinados usos discursivos. Se puede concluir por tanto que su valor semántico originario, que aparece más o menos pragmaticalizado según el contexto de uso, favorece determinados usos pragmáticos.

No obstante, su típico valor cortés no impide que guapo cumpla otras funciones en el discurso, relacionadas principalmente con el control del contacto interpersonal (cf. función fático-apelativa), o con valores expresivo-enfáticos. De todos modos, en sus demás usos vocativos el valor semántico destacado de guapo, derivado directamente del lexema de base, se relega a un segundo plano, puesto que ya no cumple el principal propósito intersubjetivo de realzar o proteger la relación interpersonal y la imagen de los interlocutores, sino que su potencial funcional se reorienta hacia otros niveles del discurso, a saber el canal comunicativo y la subjetividad. Por ende, puede postularse que en esas funciones de segundo orden el vocativo manifiesta un grado de desemantización y pragmaticalización más avanzado, puesto que se vuelve menos tangible y relevante su valor positivo de cariño y halago. Esas funciones se explicarán e ilustrarán a continuación mediante ejemplos concretos del corpus.

\subsubsection{La función fático-apelativa}

Conservando su valor cortés, guapo también puede cumplir una función fático-apelativa, vinculada con la acción de abrir, controlar y cerrar el canal

\footnotetext{
${ }^{23}$ Claro está que en este caso, el vocativo también ayuda a llamar la atención del interlocutor, en cuyo comportamiento el hablante pretende influir, y constituye por tanto un apoyo al marcador fático-apelativo al que acompaña. De todos modos, como la función apelativa ya la cumple el marcador, proponemos que el efecto pragmático principal del vocativo deba interpretarse en términos corteses.

${ }^{24}$ Evidentemente sin tomar en consideración los casos en que guapo expresa un valor negativo, de carácter excepcional.
} 
de comunicación. Esta función se vincula estrechamente con la posición en el enunciado ocupada por el vocativo, que adopta diferentes valores pragmáticos según su colocación sintáctica (Leech 1999; Jørgensen y Martínez 2010). Cabe señalar que, cuando sirve como vocativo fático, guapo tiende a situarse en posición media o final:

(12) a. E1: Y yo te voy a coger la cámara.

I1: Guapa qué tengas suertecica y que no te falte el trabajico.

E2: Muy amable. (COSER)

b. I1: Sí, y luego a continuación, pues, ¿sabes qué se hacía? Con se metía y se escaldaba en agua caliente.

E: Sí.

I1: Cociendo y con esa sangre, con un, con un saco, pues con ese saco, guapa, a freí- y se quedaban. Ahora ya no. Ahora los pelan con cal o no sé con qué dicen. Yo ahora no, ya...

E: ¿Los metían? ¿Los echan sal-, salsa aquí? Porque en Segovia a veces se echan... (COSER)

c. PEL3F1 (al teléfono): Así que nada, se lo diré que venga sobre las once y media que tú estarás aquí. ¿Vale guapa? (CORMA)

En posición inicial, los vocativos suelen cumplir la función prototípica de apelación, que consiste en identificar al destinatario del mensaje y atraer su atención. No obstante, en el ejemplo (12a), donde aparece en posición inicial de una intervención, guapa se dirige a una interlocutora ya identificada, con quien el contacto ya ha sido establecido puesto que la conversación está a punto de finalizarse. En este caso, el vocativo sirve principalmente como estrategia discursiva que facilita la toma de la palabra, permitiéndole al hablante asumir un nuevo turno de habla y restablecer la atención de la interlocutora al inicio de su intervención.

En cambio, en posición media y final, la identificación y atención del oyente ya suelen estar establecidas, así que en estas posiciones, los vocativos fáticos funcionan de manera diferente que los vocativos iniciales. En el ejemplo (12b), donde guapa se sitúa en posición media de un turno bastante largo, el hablante invoca el vocativo para poner énfasis en la información precedente y controlar el contacto con el interlocutor antes de añadir nueva información, evitando simultáneamente que el interlocutor le usurpe el turno ${ }^{25}$. Por último, en (12c), guapo sirve como marca de cierre

${ }^{25}$ Además, a esta función de control de contacto se suma un valor metadiscursivo: constituye un apoyo enunciativo que ayuda al hablante a formular su discurso, quien obviamente tiene dificultades a la hora de construir la frase, como ilustran las repeticiones, retomas de palabras y truncamientos. 
del canal comunicativo y tiende a reforzar el contacto con el interlocutor al final de su turno, constituyendo por tanto el recurso por excelencia para solicitarle una reacción al oyente e implicarle activamente en la interacción. Como se trata de una solicitud de confirmación, la necesidad de una respuesta se vuelve más tajante que en el caso de una aserción.

Por otro lado, funcionando como vocativo fático, guapo es capaz de contribuir, junto con otro marcador, a la estructuración (13a) y/o a la formulación (13b) del discurso. Así, en combinación con el marcador bueno, el vocativo contribuye al cierre de la conversación (13a), mientras que en (13b), la expresión no sé qué marca la hesitación por parte del hablante acerca de la construcción del enunciado, y junto con guapa le permite al hablante 'comprar tiempo' para encontrar las palabras adecuadas:

(13) a. CPEL3F6: Bueno guapo, me voy. (CORMA)

b. MALCE4G03: Aquí de mi niño no sé qué yo guapa no sé qué yo iba con un cacho allí. (COLAm)

\subsubsection{La función expresivo-enfática}

Como los vocativos en general, guapo también se presta, aunque de manera poco frecuente, a un uso expresivo-enfático $(\mathrm{n}=14 ; 13 \%)$. Primero, cuando se usa con un propósito expresivo, guapo expresa los sentimientos y emociones del hablante como reacción ante lo dicho o hecho por parte del interlocutor ${ }^{26}$. Por su capacidad de transmitir un abanico de sentimientos, de sorpresa y alegría hasta enfado y asombro, resulta necesario recurrir al contexto y a los rasgos prosódicos para determinar el valor expresado por el vocativo en cada caso específico. Por esta dependencia del contexto y el amplio abanico de valores emotivos que puede expresar el vocativo, consideramos el uso expresivo como el más pragmaticalizado, en el que el significado prototípico de afecto (hacia el interlocutor) se cancela más fácilmente a favor de los sentimientos y emociones que desee transmitir el hablante en el contexto concreto. Se puede observar más específicamente un movimiento funcional del nivel intersubjetivo, relativo a la relación interpersonal y al interlocutor, hacia el nivel subjetivo, relativo al propio hablante.

Como derivación de un adjetivo de belleza, evaluativo y por tanto subjetivo por naturaleza (cf. $\$ 1$ ), no sorprende que guapo se preste fácilmente a

\footnotetext{
${ }^{26}$ Cuando los vocativos cumplen una función expresiva, conforman con frecuencia el acto expresivo de manera autónoma. Esto muestra la fuerza expresiva e ilocutiva de la que van cargados los vocativos, la cual les permite combinarse con cualquier tipo de acto de habla (García Dini 1998; Edeso Natalías 2005).
} 
un uso expresivo-exclamativo. En el ejemplo (14), el vocativo expresa claramente una reacción de asombro o sorpresa ante lo dicho por parte del interlocutor:

(14) H1: Pero, maja, es que vaya cosa. Ay majas, que soñaba... soñaba

H2: ¡Guapa! que iba a la universidad.

H1: Esta- estábamos en Valdemoro, bueno, pues soñaba que íbamos a la universidad. (CREA oral)

En este ejemplo, es importante señalar igualmente las dos ocurrencias del vocativo majo, afín a guapo. Tal y como en el ejemplo (10a), el uso previo de vocativos positivos puede estimular la producción de elementos semánticamente similares, por lo que podemos hablar de un efecto 'priming'.

Luego, como recurso enfático, guapo se destina a resaltar lo dicho o el valor ilocutivo del enunciado al que acompaña, el cual corresponde muchas veces a una interjección, considerada como la construcción exclamativa por excelencia (Bañón 1993). Así por ejemplo, en (15) guapa refuerza el valor exclamativo de alegría expresado por la interjección ay sí:

(15) E: Mónica Randal, si quieres sentarte aquí.

I: Muy bien. Ay sí guapa. (CREA oral)

A diferencia de los ejemplos (8) y (9), donde las ocurrencias de guapo se han analizado como refuerzo cortés, los enunciados exclamativos no suelen ser intrínsecamente (des)corteses, de manera que en estos contextos la expresión de cortesía está relegada a un segundo plano.

También se han clasificado como usos enfáticos los pocos casos en que guapo expresa un valor negativo de irritación, ironía o retintín, como en el ejemplo (16), donde el hablante relata sobre el asombro que le había provocado a su interlocutora al revelar su edad, lo que le dio un sentimiento de superioridad:

(16) A: Marisol me dijo: «Ochenta y ocho». La meto una paliza que la doblo, fijate: «Nací en el cincuenta y cuatro guapa». Estuvo echando cuentas y todo dice: «cinco años más que yo, yo tengo».

Como se observa en este ejemplo, la intención comunicativa del hablante no es suavizar el potencial daño a la imagen de su interlocutora causado por su aserción, como en los ejemplos anteriores (10), donde el vocativo se invoca para atenuar el acto de habla potencialmente amenazante a la imagen del otro. En cambio, según el comentario del propio hablante en (16), desconcierta intencionalmente a la destinataria. En este caso y en otros similares $(2 \mathrm{~b})$, es obvio el matiz negativo aportado por parte del vocativo. 
Teniendo en cuenta las observaciones anteriores, podemos correlacionar las funciones pragmático-discursivas realizadas por el vocativo guapo con distintos grados de pragmaticalización:

\section{funciones corteses < función fática < función expresivo-enfática}

Constituyendo la función vocativa donde guapo explota su valor semánticopragmático prototípico de afecto y cariño, los usos corteses se consideran menos desemantizados que los usos expresivo-enfáticos, que explotan el potencial subjetivo y emotivo del vocativo, generando valores accidentales y secundarios, inferidos del contexto. La función fática, en cambio, se considera el paso intermedio, puesto que el valor de cariño, aunque sigue tangible, pasa al segundo plano para reorientarse hacia el contacto con el interlocutor y su implicación en la interacción, que se convierten en el centro focalizador.

Como observación final, llama la atención el predominio de guapo en el habla femenina, lo que no debería sorprender. A saber, como han puesto en evidencia estudios sociolingüísticos previos, las mujeres son más favorables al empleo de formas lingüísticas corteses y afectivas que los hablantes masculinos (Lakoff 1975; Tannen 1990). Efectivamente, los datos revelan que las hablantes femeninas se presentan como los principales usuarios del vocativo guapo $(\mathrm{n}=76 ; 70,4 \%)$, mientras que los hombres exponen un uso nítidamente menos frecuente $(\mathrm{n}=19 ; 17,6 \%)^{27}$. Además, desde el punto de vista del receptor, merece la pena señalar que utilizado por un hablante masculino, guapo se dirige en solamente dos casos a otro hombre $(10,5 \%)$, mientras que en todos los demás casos $(n=16 ; 84,2 \%)$ va dirigido a una mujer. Las mujeres, por su parte, también prefieren utilizarlo en contextos con un receptor femenino $(n=62 ; 81,6 \%)$, mientras que en solo 12 casos $(15,8 \%)$ se dirigen a un interlocutor masculino mediante guapo ${ }^{28}$. Al fin y al cabo, conforme a estas tendencias, se puede considerar guapo un 'vocativo femenino'.

27 Estos hallazgos corroboran resultados previos (De Latte y Enghels 2018), según los cuales las mujeres favorecen más el uso de vocativos cariñosos, exhibiendo un mayor deseo de mantener las buenas relaciones y realzar la relación interpersonal. Los hombres, al revés, tienden a recurrir al nombre propio para dirigirse al interlocutor, resaltando así la individualidad de este, o invocan con mayor frecuencia vocativos (de origen) tabú, como por ejemplo huevón en el español chileno (Helincks 2015).

${ }^{28}$ Estos resultados no sorprenden, puesto que entre las distintas variantes morfológicas, son las formas femeninas las que se documentan más frecuentemente (cf. §3.1.). 


\section{Conclusiones}

El análisis precedente permite formular algunas conclusiones reveladoras acerca de los usos vocativos del adjetivo de belleza guapo en el español peninsular contemporáneo.

En primer lugar, se ha proporcionado una caracterización formal y funcional del vocativo bajo análisis, la cual ha indicado algunas importantes correlaciones entre sus aspectos semánticos, formales y funcionales. Más en concreto, ha sido mostrado que guapo constituye un vocativo multifuncional, cuyo potencial pragmático-discursivo incluye usos fáticos, corteses y expresivo-enfáticos. De todos modos, se invoca principalmente como refuerzo cortés gracias a su valor halagador y cariñoso, que resulta del proceso de pragmaticalización experimentado por el adjetivo de belleza originario. El uso frecuente como estrategia de intensificación y, en menor medida, atenuación cortés sugiere por tanto la existencia de una correlación entre la naturaleza semántica de la expresión vocativa y su funcionamiento discursivo correspondiente. Es decir, conviene concluir que el contenido conceptual de la base léxica, más precisamente el sema evaluativo inherente al significado de los adjetivos de belleza, no se ha desvanecido por completo, sino que se trasluce en el valor afectivo y adulador prototípico del vocativo correspondiente, favoreciendo al nivel funcional los usos corteses.

En la misma línea de ideas, consideramos los usos corteses como los menos pragmaticalizados y desemantizados, puesto que focalizan el valor prototípico halagador y cariñoso del vocativo. En cambio, los demás usos tienden a relegar este valor prototípico de guapo a un segundo plano para enfocarse en el canal comunicativo y el contacto con el interlocutor, o en la exteriorización de los sentimientos, emociones y valoraciones del hablante. Hemos postulado por tanto que los demás usos representan grados de pragmaticalización y desemantización más avanzados.

El predominio de los valores de refuerzo y atenuación cortés se ve corroborado además por dos aspectos formales, en primer lugar, por las características distribucionales de guapo, que tiende a situarse en las posiciones media y final del enunciado, asociadas prototípicamente con valores reforzadores y atenuadores. Así, nuestros datos tienden a confirmar una correlación entre la posición y la función pragmática del vocativo, repetidamente documentada en la literatura. Segundo, los hablantes intensifican el valor cortés del vocativo a menudo mediante un afijo superlativo o aumentativo, y lo hacen en casi todos los casos para intensificar un acto agradador de imagen, reforzando de esta manera no solo el enunciado al que acompaña sino también el valor cariñoso del mismo vocativo. Por último, hemos constatado una proliferación de guapo en el habla femenina, 
de tal forma que se puede considerar guapo un vocativo 'femenino', lo que se debe fundamentalmente al carácter afectivo del vocativo estudiado.

Con todo, se espera que esta contribución anime el estudio de los vocativos, que se han quedado por demasiado tiempo fuera del interés de las investigaciones lingüísticas, a pesar de su inestimable riqueza formal y pragmática, no solo en castellano sino también en otras lenguas. Una de las labores más tajantes por realizar consiste en indagar en los rasgos fónicos que caracterizan a las expresiones vocativas, con el fin de obtener una visión más precisa y exhaustiva de sus varios efectos pragmáticos en interacciones cotidianas. 


\section{BIBLIOGRAFÍA}

Albelda, Marta, Antonio Briz, Adrián CABedo, María Estellés y Virginia GonZÁlez (2014): «Las unidades del discurso oral. La propuesta Val. Es. Co. de segmentación de la conversación (coloquial)», Estudios de lingüística española 35, 13-73.

Alonso-CoRTÉs MANTECA, Ángel (1999): «Las construcciones exclamativas. La interjección y las expresiones vocativas». En Ignacio Bosque y Violeta Demonte (eds.), Gramática descriptiva de la lengua española, Madrid: Espasa-Calpe, vol. 3, 3993-4050.

BAÑón, Antonio Miguel (1993): El vocativo: propuestas para su análisis lingüistico, Barcelona: Octaedro.

Bentin, Shlomo, Gregory McCarthy y Charles C. Wood (1985): «Event Related Potentials, Lexical Decision and Semantic Priming», Electroencephalography and Clinical Neurophysiology 60/4, 343-355.

BlaKemORE, Diane (1987): Semantic constraints on relevance, Oxford: Blackwell.

Braun, Friederike (1988): Terms of Address, Berlín/Nueva York/Múnich: Mouton de Gruyter.

BRIZ Gómez, Antonio (2012): «Los déficits de los corpus orales del español (y de algunos análisis)». En Tomás Jiménez Juliá, Belén López Meirama, Victoria Vázquez Rozas y Alexandre Veiga (eds.), Cum corde et in nova grammatica. Estudios ofrecidos a Guillermo Rojo, Santiago de Compostela: Servizo de Publicacións e Intercambio Científico da Universidade de Santiago de Compostela, 115-137.

- y Salvador PONS Bordería (2010): «Unidades, marcadores discursivos y posición». En Óscar Loureda Lamas y Esperanza Acín Villa (eds.), Los estudios sobre marcadores del discurso en español, hoy, Madrid: Arco/Libros, 327-358.

Brown, Penelope y Stephen C. Levinson (1987): Politeness. Some Universals in Language Usage, Cambridge: CUP (DOI: https://doi.org/10.1017/CBO97805118 $13085)$.

BybeE, Joan (2003): «Mechanisms of Change in Grammaticization: The Role of Frequency». En Brian D. Joseph y Richard D. Janda (eds.), The Handbook of Historical Linguistics, Oxford: Blackwell Publishing Ltd, 602-623.

Company Company, Concepción (2004): «¿Gramaticalización o desgramaticalización? Reanálisis y subjetivización de verbos como marcadores discursivos en la historia del español», Revista de filología española 84/1, 29-66.

CORLEC: Corpus oral de referencia de la lengua española contemporánea. $<\mathrm{http}: / / \mathrm{www}$. lllf.uam.es/ESP/Corlec.html>.

CuEncA, Maria Josep (2004): «El receptor en el text: el vocatiu», Estudis romànics, 39-64.

- y Joseph Hilferty (1999): Introducción a la lingüistica cognitiva, Barcelona: Ariel.

DE LATTE, Fien y Renata Enghels (2018): «La variación (socio) lingüística del vocativo en el español madrileño actual». En Martin Glessgen, Johannes Kabatek y Harald Völker (eds.), Repenser la variation linguistique: actes du Colloque DIA IV à Zurich (12-14 sept. 2016), Estrasburgo: ELiPhi, 233-248. 
— y - (2019): «La variación lingüística del vocativo en el lenguaje juvenil madrileño", Revue Romane (DOI: https://doi.org/10.1075/rro.18011.del).

Dostie, Gaétane (2004): Pragmaticalisation et marqueurs discursifs: analyse sémantique et traitement lexicographique, Bruselas: De Boeck Duculot.

Edeso Natalías, Verónica (2005): «Usos discursivos del vocativo en español», Español actual: Revista de español vivo 84, 123-142.

ENGHELS, Renata (2018): «Towards a Constructional Approach to Discourse-level Phenomena: The Case of the Spanish Interpersonal Epistemic Stance Construction", Folia Linguistica 52/1, 107-138 (DOI: https://doi.org/10.1515/flin2018-0002).

Enghels, Renata, Fien De Latte, Linde Roels y Sanne Tanghe (2016-2019): Corpus Oral de Madrid [versión digital en preparación].

—, Fien De Latte y Linde Roels (2020): «El Corpus Oral de Madrid (CORMA): materiales para el estudio (socio)lingüístico del español coloquial actual», Zeitschrift für Katalanistik 33, 45-76.

FERnÁNDEZ-OrdóÑez, Inés (dir.) (2005-): Corpus Oral y Sonoro del Español Rural. $<$ http://www.corpusrural.es $>$.

Garachana Camarero, Mar (1999): «Los procesos de gramaticalización», Moenia: Revista Lucense de Lingüistica \& Literatura 5, 155-172.

García DinI, Encarnación (1998): «Algo más sobre el vocativo», Atti del XVII convegno, Associazione Ispaniste Italiani: Bulzoni Editore, 57-62.

GHEzzI, Chiara (2014): «The Development of Discourse and Pragmatic Markers». En Chiara Ghezzi y Piera Molinelli (eds.), Discourse and Pragmatic Markers from Latin to the Romance Languages, Oxford: Oxford University Press, 10-20.

Goffman, Erving (1972): Interaction Ritual: Essays on Face-to-face Behaviour, Harmondsworth: Penguin.

Haiman, John (1994): «Ritualization and the Development of Language». En William Pagliuca (eds.), Perspectives on Grammaticalization, Ámsterdam: John Benjamins, 3-28.

HAVERKATE, Henk (1994): La cortesía verbal. Estudio pragmalingüistico, Madrid: Gredos.

HeLinCKS, Kris (2015): «La forma de tratamiento nominal huevón en Chile: análisis empírico de conversaciones cotidianas informales», Onomázein 32, 132-151 (DOI: https://doi.org/10.7764/onomazein.32.7).

HeRnández Flores, Nieves (2004): «La cortesía como búsqueda del equilibrio de la imagen social». En Diana Bravo y Antonio Briz (eds.), Pragmática sociocultural: estudios sobre el discurso de cortesía en español, Barcelona: Ariel, 95-108.

Jørgensen, Annette Myre (2008): "Tío y tía como marcadores en el lenguaje juvenil de Madrid». En Inés Olza Moreno, Manuel Casado Valverde y Ramón González Ruiz (eds.), Actas del XxхVII Simposio Internacional de la Sociedad Espanola de Lingüistica (SEL), Pamplona: Universidad de Navarra, 387-396.

- (2013): «Spanish Teenage Language and the COLAm Corpus», Bergen Language and Linguistics Studies 3/1, 151-166.

- y Juan Antonio MarTínez (2010): «Vocatives and Phatic Communion in Spanish Teenage Talk». En Jens Normann Jørgensen (ed.), Love Ya Hate Ya: The Sociolinguistic Study of Youth Language and Youth Identities, Cambridge: Scholars Publishing, 193-209. 
Kerbrat-Orecchioni, Catherine (2004): «¿Es universal la cortesía?». En Diana Bravo y Antonio Briz (eds.), Pragmática sociocultural: estudios sobre el discurso de cortesía en español, Barcelona: Ariel, 39-53.

Kleinknecht, Friederike (2013): «Mexican güey - from Vocative to Discourse Marker: A Case of Grammaticalization?». En Barbara Sonnenhauser y Patricia N. Aziz Hanna (eds.), Vocative! Addressing between system and performance, Berlín: De Gruyter Mouton, 235-268 (DOI: https://doi.org/10.1515/97831103041 76.235).

LAKOFF, Robin (1975): Language and Woman's Place, Nueva York: Harper and Row.

LEECH, Geoffrey (1999): «The Distribution and Function of Vocatives in American and British English Conversation». En Hilde Hasselgård y Signe Oksefjell (eds.), Out of Corpora: Studies in Honour of Stig Johansson, Ámsterdam: Rodopi, 107-118.

Loureda Lamas, Óscar y Lola Pons Rodríguez (2015): «Sobre la creación de la partículas discursivas en español: tradicionalidad y gramaticalización». En Michael Bernsen, Elmar Eggert y Angela Schrot (eds.), Historische Sprachwissenschaft als philologische Kulturwissenschaft, Bonn: Bonn University Press bei V\&R Unipress, 335-351.

McNally, Louise e Isidora Stojanovic (2017): «Aesthetic Adjectives». En James Young (ed.), Semantics of Aesthetic Judgement, Oxford: University Press, s. p.

Moeschler, Jacques (2002): «Connecteurs, encodage conceptuel et encodage procédural», Cahiers de linguistique française 24, 265-292.

Moliner, María (2008): Diccionario de uso del español, 2. ${ }^{a}$ ed. abreviada, Madrid: Gredos.

Mosegaard Hansen, Maj-Britt (1998): «The Semantic Status of Discourse Markers», Lingua, 104, 235-260.

Pons, Salvador (2019): Corpus Val.Es.Co. 2.1. <http:/www.valesco.es/corpus>.

Provencio Garrigós, Herminia (2016): «Cambio semántico meliorativo de guapo. De la percepción olfativa y gustativa a la percepción visual», Anuari de Filologia. Estudis de Lingüistica 6, 161-194.

Real ACAdemia Española: Diccionario de la lengua española, 23. a ed., [versión 23.2 en línea]. <https://dle.rae.es>.

- Banco de datos (CREA) [en línea]. Corpus de referencia del español actual. $<$ http://www.rae.es $>$.

- Banco de datos (CORPES XXI) [en línea]. Corpus del Español del Siglo XXI. $<$ http://www.rae.es $>$.

Seco, Manuel, Olimpia Andrés y Gabino Ramos (1999): Diccionario del español actual, Madrid: Aguilar.

TAnnen, Deborah (1990): You Just Don't Understand, Nueva York: Random House.

TANGHE, Sanne (2016): Marcadores derivados de verbos de movimiento. Una aproximación cognitiva a su polifuncionalidad, Berlín: Mouton de Gruyter.

Traugott, Elizabeth C. (1995a): The Role of the Development of Discourse Markers in a Theory of Grammaticalization. Paper presented at ICHL XII, Manchester.

- (1995b): «Subjectification in Grammaticalisation». En Dieter Stein y Susan Wright (eds.), Subjectivity and Subjectivisation, Cambridge: CUP, 31-54. 